\title{
El Humanismo como obstáculo epistemológico del Trabajo Social
}

Una lectura crítica del texto

"Humanismo y Trabajo Social" de Ezequiel Ander-Egg

ISBN: 978-987-628-279-6

María Eugenia Hermida

Licenciada en Servicio Social (UNMDP)

Especializanda en Docencia Universitaria

(UNMDP)

Doctoranda en Trabajo Social (UNR)

Profesora regular adjunta (UNMDP)

Becaria CONICET

E-mail: mariaeugeniahermida@yahoo.com.ar 
Resumen

El artículo ofrece una serie de consideraciones respecto del Humanismo, particularmente de las implicancias del mismo en el Trabajo Social. Se presenta un recorrido por los argumentos que desde una postura crítica al humanismo han elaborado autores de diferentes disciplinas y orientaciones epistemológicas, encontrando antecedentes en la filosofía anti-metafísica y antipositivista de Nietzsche, y presentando argumentos contra la emergencia de un nuevo humanismo desde la filosofía hermenéutica de Heidegger, el estructuralismo antropológico (Lévi Strauss), marxista (Althusser) y el post estructuralismo de Foucault, Derrida y Barthes. Desde este acervo conceptual se realiza un análisis epistemológico del texto "Humanismo y Trabajo Social" de Ezequiel Ander Egg, con el objeto de reflexionar, a partir de una problematización de sus contenidos, los efectos de verdad y las implicaciones para la práctica profesional que el discurso humanista produce. De esta manera se recurre a la figura bachelardiana de obstáculo epistemológico, como aquel saber incuestionado que obtura las posibilidades de un pensar-otro para la profesión. La hipótesis que se explora es que una lectura naturalizada y lineal del Humanismo puede generar que el mismo funcione como obstáculo epistemológico para las instancias de investigación e intervención del Trabajo Social.

\section{Palabras clave}

Humanismo - Obstáculo epistemológico - Trabajo Social

\section{Abstract}

This article offers a series of considerations about Humanism, particularly around its implications in Social Work. The paper offers an overview of the critical arguments about Humanism, made by some authors that come from different disciplines and epistemological orientations. Some precedents can be found in the anti-metaphysical and anti-positivist philosophy of Nietzsche. Also, in some others views that argue against the emergence of a new humanism: Hermeneutic Phylosophy (Heidegger), Anthropological Structuralism (LéviStrauss), and post-structuralism (Foucalut, Derrida, Barthes). From this heritages, we develop an epistemologic analysis of the book "Humanism and Social Work", written by Ezequiel Ander Egg. By putting into question some of the ideas in the book, we look forward to reflect about the effects of true and the implications for the professional practice of Social Work produced by the humanistic discourse. Thus, we recur to the bachelardian figure of epistemological obstacle, understood as the inquestionable knowledge that limits the possibilities of an other thinking for the profession. The hypothesis that we explore is that a naturalized and linear reading of Humanism, can turn it into an epistemological obstacle for the research and intervention in Social Work.

Key Words

Humanism - Epistemologic

obstacle - Social Work 
"Como si tuviéramos miedo de pensar el Otro en el tiempo de nuestro propio pensamiento" Michel Foucault

\section{Introducción}

Este trabajo tiene como finalidad presentar una serie de consideraciones epistemológicas respecto del Humanismo, particularmente de las implicancias del mismo en el Trabajo Social, a partir de la lectura crítica de la propuesta humanista para esta profesión de Ezequiel Ander Egg, sintetizada en un libro de su autoría del año 2010, titulado Humanismo y Trabajo Social.

Contando con antecedentes vinculados a diversas prácticas sociales, el Trabajo Social surge como disciplina científica a fines de siglo XIX y principios de siglo XX en Estados Unidos, a partir de las experiencias de trabajadoras sociales como Mary Richmond y Jane Addams. Son en especial los esfuerzos de sistematización conceptual de Richmond (1962) marcados por una fuerte impronta humanista propia de la época y particularmente de sus influencias teóricas -entre las que destacamos las figuras de Dewey (1964) y Mead (1993)los que dieron origen al Trabajo Social como disciplina y profesión reconocida en el campo académico. En este primer momento el pragmatismo y el posteriormente denominado interaccionismo simbólico marcaron las orientaciones conceptuales que guiaron a las denominadas pioneras del Trabajo Social, que por su parte adscribieron también a diversos movimientos de la época como fueron el sufragismo, la lucha por el voto, la defensa de las minorías raciales, la resistencia a la Gran Guerra, y el feminismo. Vemos entonces que el Humanismo como corriente circula en la profesión desde su mismo surgimiento (Miranda Aranda, 2010; 2013).

En las décadas que se sucedieron, el Trabajo Social se fue reinventando, en claro diálogo con las diferentes manifestaciones de la cuestión social a la que hubo de responder, pero también a las distintas perspectivas conceptuales de las ciencias sociales. Así hicieron pie en 
la profesión diversas propuestas entre las que pueden contarse la fenomenología, el psicoanálisis (particularmente en su versión kleiniana), el funcionalismo, diversas versiones del marxismo, los enfoques sistémicos, el constructivismo, así como distintas corrientes críticas a las teorías modernas como el postestructuralismo, las teorías posmodernas y en los últimos años el giro decolonial, entre otras.

La propuesta de un Trabajo Social Humanista en la actualidad es sostenida por distintos autores ${ }^{1}$ y sus diversas producciones -así como también la perspectiva filosófico-teórica que subyace en ellaspueden encontrarse con facilidad en los distintos programas de asignaturas de las carreras de Trabajo Social en distintas universidades. No podemos sin embargo trazar una línea directa de correspondencia entre las actuales propuestas humanistas y la impronta humanista del Trabajo Social en sus inicios en Estados Unidos. En principio porque, como veremos más adelante, las propuestas humanistas actuales (particularmente la de Ezequiel Ander-Egg) cuentan con una clara influencia del pensamiento de corte religioso -de inspiración católica- y filantrópico. En el caso de los escritos de las denominadas pioneras, y particularmente en el caso de Mary Richmond, se las experiencias de participación previa de la autora y sus influencias estuvieron más vinculadas con los sistemas de ayuda protestantes, y en absoluto con el catolicismo, y que su interés fue el de laicizar las prácticas de ayuda. Distinta es la situación si analizamos las mutaciones que el Trabajo Social experimentó en su constitución disciplinar al ingresar como profesión reconocida en nuestros países sudamericanos. En ese caso se produjeron hibridaciones entre la propuesta sistematizada por Richmond y las prácticas higienistas que desde la constitución de nuestros Estados venían realizándose en nuestros territorios, cuyos discursos legitimantes provenían en gran medida de las máximas morales de la Iglesia Católica. Sin embargo, este tema

1 Dado que lo que aquí se propone es un análisis epistemológico de un texto en particular -Ander Egg, Ezequiel (2010) Humanismo y Trabajo Social-las diferentes apreciaciones que se realizan no pretenden alcanzar un carácter representativo de la propuesta humanista en su conjunto para la profesión. De todas formas no puede obviarse al menos la mención de otros autores que se han definido como humanistas, entre ellos Enrique Di Carlo, particularmente su texto El paradigma humanista como sustancia del Trabajo Social. A su vez, se han encontrado en la Web sendos artículos sobre el Humanismo y el Trabajo Social en Chile, rescatando la propuesta humanista de Silo. 
no está cerrado y es parte de la agenda de fructíferos debates actuales en la profesión ${ }^{2}$.

Dentro de la variada gama de textos que se inscriben en la propuesta humanista en la actualidad, se seleccionó entonces para el análisis en este trabajo el libro Humanismo y Trabajo Social de Ezequiel Ander-Egg, con el objeto de reflexionar, a partir de una problematización de sus contenidos, los efectos de verdad y las implicaciones para la práctica profesional que el discurso humanista produce ${ }^{3}$.

La selección de este texto está fundamentada en sendos motivos. Por un lado, si bien son varios los escritos que tematizan sobre el Humanismo de forma más o menos directa, éste es el único texto que aborda el Humanismo como contenido central para el Trabajo Social. Por otra parte, es de edición reciente. Por último, y aludiendo a la denominada función autor (Foucault, 1998) y su "efecto de producción de verdad", entendemos que es un escrito que cuenta con la legitimación que le brinda la rúbrica de Ezequiel Ander-Egg. Este autor, de vasta y leída producción, cuenta con amplia aceptación por una parte no menor del colectivo profesional, y habiendo estado activo en la producción de textos desde hace más de cuatro décadas, sigue vigente y su influencia se reedita en tanto sigue formando parte de las lecturas que componen programas y planes de estudio actuales.

La hipótesis que se explora en este trabajo es que una lectura naturalizada y lineal del Humanismo puede generar que el mismo funcione como obstáculo epistemológico ${ }^{4}$ para las instancias de investigación e intervención del Trabajo Social.

2 Entre quienes sostienen que el Trabajo Social en sus orígenes estuvo directamente influenciado por las prácticas religiosas filantrópicas encontramos las posturas de Martinelli (1992) y Netto (1992). Desde otra postura, los análisis de Miranda Aranda $(2010 ; 2013)$ y Travi (2011) ofrecen argumentos para sostener el carácter laico de la propuesta de las pioneras. En relación con el surgimiento del Trabajo Social en nuestro país, y los discursos que legitimaron su accionar, observamos también diferencias entre las propuestas de Parra (2001) y Carballeada (2006).

3 Se hará alusión también al texto "Desafíos, encrucijadas y crisis del Trabajo Social a comienzos del silgo XXI" del mismo autor, editado también en 2010 y entregado como material de lectura previo a los estudiantes y docentes que participaron de la charla que diera en la UNMDP en el mes de abril de ese año.

4 Se rescata la noción bachelardiana de obstáculo epistemológico (Bachelard, 2004), que junto con la de ruptura epistemológica nos permite pensar el conocimiento como ruptura con el error, rebatiendo la idea del conocimiento como movimiento acumulativo. Esta propuesta nos permite pensar un Trabajo Social que se re-conoce, se re-conceptualiza, rompiendo mandatos pasados, construyendo nuevos desafíos. 
Las reflexiones que aquí se presentan se realizan a la luz del debate humanismo/antihumanismo -particularmente en su dimensión teórico-epistemológica-iniciado en el marco de la segunda posguerra al interior de las ciencias sociales. Las ideas que se discuten están orientadas por los argumentos que desde una postura crítica al humanismo han elaborado autores ${ }^{5}$ provenientes de diferentes disciplinas y orientaciones epistemológicas derivadas del giro lingüístico: encontrando antecedentes en la filosofía anti-metafísica y anti-positivista de Nietzsche, y presentando argumentos contra la emergencia de un nuevo humanismo desde la filosofía hermenéutica de Heidegger, el estructuralismo antropológico (Levi Strauss), marxista (Althusser) y el post estructuralismo de Foucault, Derrida y Barthes.

\section{La irrupción del debate humanismo/antihumanismo en el siglo XX}

El Humanismo como corriente de pensamiento cuenta con siglos de historia. Se entiende que su surgimiento se da en el marco de la cultura griega reinterpretada por el Imperio Romano y rescatada como propuesta en el Renacimiento. A la mirada teocéntrica propia del medioevo se reacciona con la propuesta antropocéntrica del Humanismo.

Hoy entendemos que no existe "un" Humanismo, dado que esta visión ha sido reinterpretada desde diferentes matrices epistemológicas, aunque cuenta con un ethos común, condensado básicamente en lo que entendemos como Racionalidad Occidental Moderna, y particularmente, el rescate de la Aufklarung, la Revolución Francesa, la reivindicación de la búsqueda por el sentido de "lo humano" y el compromiso en la acción con ese sentido desde una mirada teleológica. De esta forma todas las disciplinas y profesiones que se

5 Existen otros autores que han hecho una contribución inestimable a este debate y que en este trabajo no son citados. Tal es el caso de la lectura sobre el sujeto desde el psicoanálisis de Lacan, entre otros. A su vez, de los autores que sí están presentes aquí, sólo rescatamos parte de sus planteos. Esto se debe a que el foco está en rescatar algunos de los argumentos que puedan aportar a la lectura crítica de textos sobre Humanismo y Trabajo Social. 
gestan al calor de la Modernidad y ven la luz precisamente a partir del triunfo del Iluminismo y la Revolución Francesa, tienen en sí el germen del Humanismo como filosofía que las atraviesa. Se puede observar con claridad esto en todas las ciencias sociales, y entre ellas, el Trabajo Social, como apuntáramos párrafos antes. Sin embargo, que las disciplinas sociales hayan sido atravesadas desde sus inicios por el pensamiento humanista, tanto en sus versiones anglosajonas como europeas, no implica que hayan hecho de este factum un problema de reflexión. Es decir que en tanto el humanismo era la lengua franca de las ciencias sociales, no fue constituido como objeto de crítica, sino como forma de acercarse al tratamiento de lo humano. Habría que esperar algunas décadas para que el humanismo sea configurado como pregunta y como eje para diversas críticas. Nos interesa aquí entonces describir en algunas líneas lo que significó para el campo de las ciencias sociales el resurgimiento del debate en torno al Humanismo en la segunda posguerra.

Este debate a mediados del siglo pasado probablemente no se hubiera dado con la misma profundidad si no hubieran existido los escritos de Nietzsche de fines del siglo XIX. Al respecto podemos leer en la "Gaya Ciencia" sus reflexiones en torno a lo que es o no es el hombre: "El hombre ha sido educado por sus errores: en primer lugar, nunca se veía de otro modo que incompleto. En segundo lugar, se atribuía propiedades inventadas; en tercer lugar, se sentía en un rango equivocado respecto del animal y la naturaleza; en cuarto lugar, inventaba siempre nuevas tablas de bienes y las tomaba durante un cierto tiempo como eternas e incondicionadas (...) Si se elimina del cálculo los efectos de esos cuatro errores, queda eliminada también toda idea elevada acerca de la condición humana, la humanidad y la "dignidad del hombre" (Nietzsche, 2004:114-115).

Tomando como base (por coincidencia o por oposición) estas apreciaciones que revolucionan el sentido atribuido al hombre en la filosofía, diferentes autores ingresaron a la cuestión del Humanismo. Seleccionamos, a lo fines de explicitar los diversos argumentos en torno a este debate, los aportes, confrontaciones y propuestas de los 
actores de mayor peso en la problemática a mediados del siglo XX: Heidegger, Lévi Strauss, Sartre.

¿Por qué resurge el tema del Humanismo luego de finalizada la Segunda Guerra Mundial? Haciendo un apretado resumen podemos decir que la posguerra dejó en el campo de las ciencias sociales los interrogantes respecto de lo humano, respecto de la barbarie, respecto, en fin, de la posibilidad de creer en algo, de atribuirle un sentido a la vida después del horror de la guerra que no pudo (o no quiso) ser evitado.

En este contexto es que emerge Carta sobre el humanismo escrita por Heidegger en 1946 en respuesta a la pregunta que le formulara Jean Beaufret: "Comment redonner un sens au mot "Humanisme?". Frente a esta pregunta Heidegger responde con otra, interrogándose sobre la conveniencia o necesidad de seguir manteniendo la palabra "Humanismo" dado que para él era evidente el daño que provocaba este tipo de conceptos. Tomando las nociones de valor, objeto, sujeto, ente y ser, desarma la estructura de pensamiento que propone el Humanismo, otorgando a ciertas realidades el título de valores a preservar: "El pensar contra «los valores» no pretende que todo lo que se declara como «valor»-esto es, la «cultura», el «arte», la «ciencia», la «dignidad humana», el «mundo» $\mathrm{y}$ «dios»- sea carente de valor. De lo que se trata es de admitir de una vez que al designar a algo como «valor» se está privando precisamente a lo así valorado de su importancia. Esto significa que, mediante la estimación de algo como valor, lo valorado sólo es admitido como mero objeto de la estima del hombre (...). El peregrino esfuerzo de querer demostrar la objetividad de los valores no sabe lo que hace. Cuando se declara a «dios» el «valor supremo», lo que se está haciendo es devaluar la esencia de dios (...) pensar contra los valores no significa proclamar a son de trompeta la falta de valor y la nulidad de lo ente, sino traer el claro de la verdad del ser ante el pensar, en contra de la subjetivización de lo ente convertido en mero objeto" (Heidegger, 1947:20,21).

En esta línea, Heidegger plantea una discusión con el Humanismo en tanto que el esfuerzo de esta perspectiva por erigir y custodiar ciertos valores, genera el efecto contrario al supuestamente buscado: se 
objetualiza lo que en sí encierra la posibilidad de ser conceptualizado como valor, pasa al plano del ente, siendo separado del Dasein (el ser arrojado al mundo). El lenguaje es la casa del ser. Hay que liberar al lenguaje de la lógica y la gramática, de la escisión entre objeto y sujeto. La poesía permite el acceso a eso no pensado por la filosofía por siglos: el ser. La angustia y el arte, más que el cumplimiento de un orden, permite el acceso a eso que confusamente llamamos lo humano.

Emerge, en este contexto con fuerzas, en el marco de las ciencias sociales y la filosofía, el cuestionamiento al cogito cartesiano, particularmente en la respuesta (desarrollada en el capítulo final de su libro El pensamiento salvaje) que Lévi Strauss dedica al libro de Sartre Crítica de la razón dialéctica. ¿Cuál es entonces el peligro del Humanismo? A la crítica más difundida, basada en llamar la atención sobre los caracteres etnocéntricos del humanismo, básicamente el rescate del sentido de "hombre" como animal racional (Aristóteles) entendiendo por Razón, la razón moderna y por tanto eurocéntrica, a la que De Souza Santos (2005) define como perezosa, indolente, metonímica y proléptica, hay que agregar otro tipo de críticas. Y son las que definen al humanismo como mito ${ }^{6}$ y como ideología. La antropología estructural de Lévi Strauss (2009) plantea la disolución del hombre antes que su construcción o explicación afirmando que “todo Mito es una búsqueda del tiempo perdido". En este caso será la Revolución Francesa el tiempo perdido resignificado, el Mito funcionando en un pasado-presente-futuro, dotando de sentido y reconvirtiéndose en ideología en tanto reclama para sí la universalidad de sus banderas. La propuesta de la antropología estructural es plantear la disolución del hombre en tanto esfuerzo teórico de pensar lo social por fuera de los mitos. Porque el Mito instaura un Orden que permite conjurar lo Otro. La Historia como Mito impone un Orden determinado al dotar de sentido particular el tiempo que fue, el que es y el que vendrá. Lo Otro debe encajar con este sentido. Esto genera en términos de Bourdieu (2003) violencia simbólica. La propuesta diver-

6 Para un desarrollo preciso sobre las implicancias teóricas el concepto de Mito, y particularmente de la función de los Mitos en el marco del Trabajo Social, cfr. González-Saibene (2007). 
gente a este planteo Humanista es, para Levi Strauss, partir de que ya no es el hombre el objeto de estudio sino el lenguaje, y principalmente su estructura, sistema que dota de sentido aquello que nomina, aunque en sí mismo no lo tenga.

Esbozando algunas de las coordenadas de este rico debate, podemos pensar ciertos conceptos que se hicieron presentes en esta polémica haciendo jugar las tensiones que entre sí se desatan:

- Orden/Barbarie

- Sentido/Sistema

- Historia/Estructura

- Tiempo/Espacio

- Homogeneidad/Diferencia

- Lo Otro/Lo Mismo

- Constituir el hombre/Disolver el hombre

De esta forma las posturas humanistas tenderán en rasgos generales a apelar al orden que permita desarrollar los valores humanistas, poniendo freno a las prácticas bárbaras de aquellas culturas inferiores. Elevará la noción de sentido frente a la de sistema, entendiendo el sentido como valor prestablecido a las prácticas y a los objetos, y al que se puede acceder por medio de la razón. El tiempo prevalecerá sobre el espacio, en tanto tiempo-mito, tiempo lineal, teleológico, que expande el futuro y contrae el presente (De Souza Santos, 2005). La homogeneidad de la "raza humana", avalada por los ideales universalistas de la Revolución Francesa, pondrán un tope al reconocimiento de la diferencia, ese tope es el de la tolerancia, que impide un verdadero acercamiento a lo Otro en tanto Otro. En esta línea lo humano es tarea, desafío, interpelación, porque es en definitiva el proyecto inacabado de la Modernidad, al que el Humanismo como ideología está llamado a responder: es la construcción del hombre y de las banderas de la igualdad, la fraternidad y la libertad.

Pero no son sólo las ideas de Nietzsche, Heidegger y Lévi Strauss las que ponen el foco en una crítica al Humanismo. También dentro de la tradición marxista encontramos voces que alertan sobre el re- 
duccionismo al que puede llevar una mirada humanista en ciencias sociales. Así Althusser, al analizar la producción teórica de Marx, sostiene que su obra puede dividirse en dos momentos, antes y después de la ruptura epistemológica que según Althusser se dio en Marx en el año 1845. A partir de ese momento "Marx rompe radicalmente con toda teoría que funda la historia y la política en la esencia del hombre. Esta ruptura comporta (...) la crítica radical de las pretensiones teóricas de todo humanismo filosófico [y la] la definición del humanismo como ideología" (Althusser, 2004:187-188). Su lectura de Marx, opuesta a la de Sartre (quien desde el marxismo recupera el Humanismo no como esencia sino como posibilidad de realización desde la libertad ejercida por el hombre), es directamente anti humanista, denunciando el carácter ideológico del mismo.

\section{Algunas notas sobre la lectura post estructural del Humanismo}

El post estructuralismo en sus diferentes versiones, plantea un debate con las corrientes humanistas. Si cotejamos las críticas al Humanismo, comparando las foucaultianas por un lado, y las provenientes del estructuralismo ya sea althusseriano como el de Levi Strauss por el otro, podemos advertir que una diferencia central está en el uso de las nociones de ideología y de discurso.

En el post estructuralismo el tema es la verdad: el humanismo instaura una verdad, la verdad de la esencia humana, ese algo interior que nos une en tanto iguales en nuestro ser sujetos, y nos une en tanto horizonte a custodiar. Vehiculiza en la imagen universalista del Hombre los rasgos de la Razón Moderna Occidental. Estado, Capital y Modernidad gestan el Humanismo que emerge en el Renacimiento antropocentrista liberador del yugo medieval, y se expande en sus efectos en la Ilustración, en la Revolución Francesa tal como hemos afirmado.

Foucault explica por qué prefiere no utilizar la noción de ideología, y argumenta tres razones. En principio que, "se quiera o no, está 
siempre en oposición virtual a algo que sería la verdad" (Foucault, 1976:182). Al respecto manifiesta que su preocupación no es tanto la de separar lo científicamente verdadero de lo que no lo es al interior de un discurso, sino más bien, la de analizar los efectos de verdad que se producen en los discursos mismos, que no son en sí ni verdaderos ni falsos. En segundo lugar, plantea el inconveniente de que "se refiere, pienso, necesariamente a algo como un sujeto" (Foucault, 1976:182). Pensemos aquí en la crítica foucaultiana a la noción de sujeto como ser preestablecido, y al reconocimiento que en contraposición da a los discursos como aquellos que tejen subjetividades. Por último advierte que en la noción de ideología, ésta emerge como un algo secundario respecto de la infraestructura económica que la determina.

Respecto de la emergencia y permanencia del sujeto como posibilidad, la función de la conciencia histórica es central en Foucault. En su Arqueología del saber manifiesta que esta cuestión de la reconstrucción histórica desde una mirada teleológica, orientada a buscar orígenes, causas pasadas, antecedentes, evoluciones, tuvo como objeto "salvar, contra todos los descentramientos, la soberanía del sujeto, y las figuras gemelas de la antropología y del humanismo" (Foucault, 1995:21).

Una de las ideas centrales que plantea Foucault para poder comprender sus observaciones respecto del Humanismo, es la de la emergencia del hombre. Al respecto afirma que: "El umbral de nuestra modernidad no está situado en el momento en que se ha querido aplicar al estudio del hombre métodos objetivos, sino más bien en el día en que se constituyó un duplicado empírico-trascendental al que se dio el nombre de hombre" (Foucault, 2002:310). El hombre es un fenómeno reciente, emerge como noción y como materialidad para nuestro saber junto con la Modernidad7, y la escisión constituyente del hombre es la de lo empírico y lo trascendental, como momentos diferentes, irreconciliables, pero necesarios para entender lo humano

7 En su texto Las palabras y las cosas Foucault diferencia los momentos históricos de lo que denomina la "época clásica" o "prehistoria" que va desde el siglo XVII al XIX y la modernidad, o momento contemporáneo, desde el siglo XIX -particularmente desde Nietzsche- y en vigencia al momento en que presenta sus argumentos. 
como integralidad. La reducción (empirismo, positivismo) y la promesa (escatología, crítica). La paradoja debe ser ocultada. El discurso del Humanismo guardará este secreto. El análisis de lo vivido, campo donde se libra la batalla de estos dos ejes, une lo que es del orden del cuerpo con el orden de la cultura. En este campo Foucault ubica al positivismo, al marxismo -como incorporado al positivismo-, así como la escatología y la fenomenología.

Surge el hombre pero surge en el mismo movimiento lo Otro, lo impensado, lo inconsciente. Esta alteridad peligrosa y oscura, no es una noche que se aloje dentro del hombre que emerge, sino que aparece a su lado, diferente y necesaria. Lo impensado como sombra del hombre, aparece en el hueco que dejan los argumentos ajados del cogito cartesiano y del análisis trascendental kantiano. El pensamiento moderno quiere pensar lo impensado, y así Marx lo nombra como "hombre alienado", es a su vez el "sedimento" en la fenomenología husserliana, o para el psicoanálisis el hombre trastocado por compulsiones derivadas de un inconsciente al que no controla. Frente a esta compulsión por nominar lo impensable, Foucault propone el vacío: "Actualmente sólo se puede pensar en el vacío del hombre desaparecido. Pues este vacío no profundiza una carencia; no prescribe una laguna que hay que llenar. No es nada más, ni nada menos, que el despliegue de un espacio en el que por fin es posible pensar de nuevo" (Foucault, 2002:333).

Respecto del enfoque de la deconstrucción, también asociado al pensamiento post estructural, encontramos otra vez propuestas críticas al Humanismo. Así es como Derrida plantea que nos hemos apropiado de la filosofía platónica pero no del texto. Que hemos reunido una compilación de argumentos lógicos y ciertas reflexiones, escindidas del texto. Esto mitologiza el canon e impide la lectura de las rupturas. Con referencia a la tesis de Platón ilustrada en el mito de la caverna, estos dos mundos visible e invisible, paralelos e irreductibles entre sí, Caputo plantea que "Derrida no buscará, como lo hiciera Hegel, una reconciliación dialéctica sustentadora de las dos en una tercera forma superior, un universal concreto que contenga la verdad de los primeros dos. En lugar de ello buscará (en el tex- 
to mismo) algún tercer elemento que la distinción omita, alguna no verdad, o apenas un dejo de la verdad que caiga fuera de la famosa distinción, que la verdad de cualquiera de los dos por separado o ambas juntas no llegue a aprehender, que no sea ninguna de las dos y ambas a la vez" (Caputo, 2009:103). Otra vez encontramos el vacío, lo impensable, la crítica al hombre como paradoja entre lo empírico y trascendental, en tensión entre dos polos no dialectizables. Ésta es la crítica al logocentrismo, tan caro al Humanismo. Desde el enfoque de la deconstrucción podríamos plantearnos: ¿Qué hay de lo humano que no es "lo humano logo céntrico"? ¿Qué es el hombre que no sea del orden del "animal racional”? ¿Cuál es esa abertura, ese hueco, esa no verdad, que la ideología del Humanismo no nos permite ver?

\section{La utopía en el Humanismo, la heterotopía en Foucault y la atopía en Barthes}

Frente al valor destacado que el Humanismo brinda a la utopía como ideal, como consigna generadora de movimiento, como canal de acercamiento a la concreción de ese telos histórico al que se tiende, Foucault propone la noción de heterotopía. A partir de la exquisita relectura que realiza de "El idioma analítico de John Wilkins" de Borges, aborda, (retomando esa imposible taxonomía que el escritor argentino describe al aludir a "cierta enciclopedia china" que clasifica los animales) lo que se manifiesta en el orden de lo impensable. Lo Mismo y lo Otro se vuelven imposibles de ser pensados desde esta taxonomía escandalosa donde no puede ser observado el criterio mismo de clasificación: "animales que i) se agitan como locos, j) innumerables, k) dibujados con un pincel finísimo de pelo de camello" (Foucault, 2002:2).

El autor pone en tensión estas dos categorías: utopía y heterotopía. La una ilustrando un horizonte imposible revestido de posibilidad normativa, de ideal por el cual suspender el presente en pos de un futuro prometido (en tanto pensado se percibe ya su gusto, tranquiliza ya que "si lo pienso existe"). La otra desvelando lo imposible justo 
en el lugar mismo en el que creíamos tener la certeza de lo previsible. "Las utopías consuelan: pues si no tienen un lugar real se desarrollan en un espacio maravilloso y liso; despliegan ciudades de amplias avenidas, jardines bien dispuestos, comarcas fáciles aun si su acceso es quimérico. Las heterotopías inquietan, sin duda porque minan secretamente el lenguaje, porque impiden nombrar esto o aquello, porque rompen los nombres comunes o los enmarañan, porque arruinan de antemano la 'sintaxis' y no sólo al que construye las frases- aquella menos evidente que hace 'mantenerse juntas' (unas al lado o frente de otras) a las palabras y las cosas" (Foucault, 2002:3). De esta forma, las posibilidades de explorar heterotopías, como prácticas disruptivas y no como horizontes prometidos, serán abordables sólo en tanto y en cuanto nos desliguemos de las pretensiones utopistas del Humanismo, que clasifica aquello que es, aquello que puede ser, y aquello que es deseable hacer para acceder al paraíso prometido.

Otra noción de interés para este análisis es la de atopía, propuesta por Barthes. La encontramos en su obra Fragmentos de un discurso amoroso. Átopos, el no lugar. Mientras la heterotopía denota la imposibilidad de clasificar, la atopía señala la imposibilidad de calificar. La heterotopía implica sumergirse en un lugar descentrado, que resiste las taxonomias, es irreductible. La atopía no resiste un predicado. Es. No puede ser ampliada, adjetivada. El ser amado en Barthes es átopos, es único, y lo único hace estallar nuestra clásica forma de nominar y describir, el mandato Aristotélico de género próximo y diferencia específica. "La atopía resiste a la descripción, a la definición, al lenguaje que es maya, clasificación de los Nombres (de las Faltas). Atópico, el otro hace temblar al lenguaje: no se puede hablar de él, sobre él; todo atributo es doloroso, torpe, mortificante: el otro es incalificable (ese sería el verdadero sentido de átopos). Frente a la originalidad brillante del otro no me siento jamás átopos, sino más bien clasificado" (Barthes, 2009:52-53).

La casa del ser es el lenguaje, advierte Heidegger (1987). Y el lenguaje es desafiado por heterotopías y atopías, movimientos que irrumpen en lo naturalizado, que desentrañan la arbitrariedad de lo dado, que permiten construir lo nuevo, generar transformaciones. No 
será entonces la utopía el horizonte que promueva cambios desde las propuestas post estructurales, ya que constriñe las posibilidades del lenguaje haciendo presente un singular universalizado que degustamos antes de vivirlo.

En estas reflexiones donde emergen las críticas a las taxonomías y las descripciones lineales, se percibe el juego inacabado de lo Mismo y de lo Otro. El saber como dominio preexistente a la ciencia, generado por prácticas discursivas, el saber como espacio que posibilitó la emergencia de ciertos criterios para delimitar las clasificaciones, las palabras y las cosas, hace que la historia del orden de las cosas sea la historia de lo Mismo, mientras la locura, lo abyecto, lo indecible sea ese lo Otro.

\section{Bases de la propuesta humanista de Ander-Egg al Trabajo Social}

En el inicio de su texto Ander-Egg consigna a quiénes va dirigido su libro y quiénes no son destinatarios del mismo ${ }^{8}$. Respecto de los primeros, afirma que son aquellos profesionales que buscan desarrollar las potencialidades de la profesión. En este marco, incorpora lo que denomina las tres ideas básicas que subyacen a todo su posterior análisis. La primera es: "A diferencia de otros quehaceres profesionales, en el Trabajo Social importan, de manera especial, las características y las cualidades de quienes deben realizar este tipo de tareas" (2010a:15). Esta afirmación ya requiere alguna consideración. Hay un centramiento en el profesional y particularmente en sus cualidades.

8 Haciendo uso de argucias retóricas, el autor, luego de manifestar que su propuesta es una entre muchas, y que está abierto al diálogo y al intercambio, ya que todo conocimiento es provisorio, a continuación desestima de ante mano cualquier crítica a su planteo diciendo: "Seria pretencioso pretender hablar para todo el cuerpo profesional. No escribo para: "las personas adocenadas y frívolas, los cientificistas y los tecnócratas, para los que sólo buscan adquirir estatus profesional (...) nunca podrá aparecer en el horizonte de su pensamiento la idea de un trabajo social testimonio de lo humano. Para los desesperanzados - nihilistas, cínicos, trepadores, oportunistas- (...), los trabajadores sociales que no tienen ninguna inquietud, salvo la de cobrar un sueldo" (Ander Egg, 2010a:16) Es decir que mediante un recurso metonímico el autor toma la parte por el todo, reduciendo a todo aquel que intente hacer una lectura crítica de su obra al plano peyorativo del tecnicismo, el oportunismo, el conservadurismo. 
Éstas, tal como se verá en el desarrollo de su libro, no tienen que ver con aptitudes intelectuales o técnicas sino con su adhesión a un estilo de vida humanista. En el siguiente extracto se observan con claridad estas ideas: "Para que el Trabajo Social sea una profesión identificada -no sólo integrada- a la problemática real de los oprimidos, más que una racionalidad científica, nos exige sentir la necesidad vital de romper con un sistema intolerable, ser parte -no sólo partícipe- de un proceso humanizador (...) Los millones de seres humanos que no pueden vivir como personas, son también mis hermanos y hermanas, mis compatriotas de la Patria-Tierra... Si no me inquieto y no hago algo, Caín soy yo, que con mi indiferencia asesino a mis hermanos (...) [El hombre] sobre todo es: alguien que tiene más necesidad de comunión humana que de calorías y de encuestas" (2010a:35-36).

El autor propone la adhesión al Humanismo como canal para un ejercicio comprometido de la profesión desestimando la racionalidad científica. A continuación, apelando a figuras religiosas, moraliza el ejercicio profesional, manifestando que "con mi indiferencia asesino a mis hermanos". Los conflictos sociales, de clase, económicos, los desarrollos intelectuales provenientes de investigaciones científicas que buscan comprender y explicar los fenómenos sociales, quedan dejados de lado. La responsabilidad respecto de lo que él denomina la problemática real de los oprimidos, está en la indiferencia del profesional, él es el que asesina, no las estructuras. Para terminar manifiesta, otra vez apelando a la estética cristiana, que el hombre necesita más de comunión que de investigación (encuestas) o intervención vinculada a posibilidad de acceso a recursos básicos (calorías). Unas páginas más adelante desarrolla esta idea sosteniendo que: "Hablar del Trabajo Social como profesión testimonio de la humanidad (...) se trata de una opción vital que va más allá de la ciencia y de la metodología, o de las opciones políticas o ideológicas que podamos hacer" (2010a:38).

"A la pregunta que suele formularse si los seres humanos son buenos o malos, la historia, las ciencias humanas y lo que conocemos por propia experiencia, sabemos que nos movemos entre esas dos posibilidades, y que, en última instancia, somos cada uno de nosotros quie- 
nes escogemos" (Ander-Egg, 2010a:43). Otra vez la responsabilidad se individualiza. Desde un enfoque maniqueo -sustentado desde el Humanismo- se sostiene que hay algo como "un" Bien y "un" Mal, algo preexistente a lo que "cada uno" de nosotros "elegimos" o no "adherir". Recordemos la lectura de Heidegger sobre la cosificación de los valores como mecanismo que termina desvalorizándolos como objetos ajenos al sujeto. También se observa un universalismo en esta apreciación ya que se pierde el esfuerzo que muchos profesionales hacemos al intentar significar las prácticas y discursos en sus contextos, entendiendo que lo que es un Bien para la racionalidad occidental o la cultura hegemónica, no necesariamente lo sea para todos.

Para Ander-Egg, el Trabajo Social como testimonio de lo humano, es una posibilidad de ser de la profesión que se juega en el estilo de vida que "cada uno" de los trabajadores sociales lleve adelante. Para esto, el autor hace algunas propuestas: dentro de las expresiones de un estilo de vida humanizado y humanizante, el autor enumera ocho. Citamos algunas:

- "Estar motivado y vivir conforme a los valores humanos más altos: solidaridad, bondad generosidad.

- Haber encontrado un sentido a la existencia.

- Un modo de ser que manifiesta serenidad, expresión de su paz interior y exterior.

- Ser rebelde contra todo lo injusto.

- Cuidar su cuerpo para que permanezca sano y favorezca el equilibro mental, los pensamientos positivos y la alegría de vivir" (Ander-Egg, 2010a:44).

Sin forzar la letra del autor, creo que podemos encontrar similitudes asombrosas con los textos actuales vinculados con lo que se da en llamar Autoayuda o New Age (Osho, Chopra, etc.). La ecuación es simple: si cada uno de nosotros lleva un estilo de vida humanizador, la sociedad cambiará. Aquí lo preocupante no es la propuesta en sí misma, que en todo caso puede ser o no interesante para cada quién, sino que esta propuesta se esgrima como fundamento de un 
profesión, que debiera sustentar su conocer y su hacer en las ciencias sociales y no en hábitos personales, y que tiene un campo de acción que va más allá del propio estilo de vida o conocimiento personal de cada profesional.

En relación a las propuestas de formación de grado para lograr esta profesión testimonio de lo humano, el autor sostiene que es importante: "No hacerle perder el tiempo a los estudiantes en largas y complicadas explicaciones sobre epistemología (...) ¿Algún estudiante de Trabajo Social, sociología o cualquier ciencia tiene planteados problemas epistemológicos?” (Ander-Egg, 2010b:7).

Respecto de los denominados por el autor "virus" de la profesión, encontramos lo que él llama delirio intelectualoide 9 . En general aparece en docentes dedicados de lleno a la vida académica, que otorgan un valor sustantivo a "una sólida formación teórica, acompañada de producción de conocimientos a partir de la investigación que nos permita analizar políticas sociales globales y sectoriales en relación con los planes económicos vigentes" (Ander-Egg, 2010a:11). Frente a esta forma de entender la formación académica, Ander-Egg se pregunta: “¿Cuántos trabajadores sociales conocen que hayan sido contratados para estas tareas?" (2010a:11). Este punto se conecta con lo que el autor denomina "demanda laboral y demanda social". La primera implicaría la demanda surgida de los campos de acción clásicos de la profesión. La segunda se inscribe en un "segmento del mercado" que responde a nuevas necesidades o demandas de consumo. Ander-Egg propone redefinir la formación en vistas de la posibilidad de obtención de un puesto de trabajo específico de la profesión. No creo que sea necesario redundar en las consecuencias que tiene y ha tenido esta

9 Además de la crítica que el autor realiza a una formación sólida e integral en políticas sociales, también alude a otros supuestos desvíos. "Otro de los delirios es considerar "la intervención social como gramática" y, a parir de ello, ofrecer "una semántica propositiva del Trabajo social frente a los desafíos de la globalización. (???)" ( ; signos de interrogación del autor). Se entiende (aunque no sea citada la autoría de estas consideraciones que Ander Egg critica), que hay una clara alusión a la propuesta de Tere Matus, y por intermedio de ella, a los análisis provenientes de la hermenéutica o el posestructuralismo que rescatan los conceptos de gramática o semántica, que entienden en fin, que la realidad no es sólo lo empírico observable, que, como diría Nietzsche "no hay hechos sino interpretaciones de los hechos". En contra de esta visión Ander Egg insiste: “pensar más la existencia que pensar los libros” (2010a:14). Como si nos vinculáramos con la existencia de forma directa, sin la mediación de categorías, sean éstas teóricas o del sentido común. 
visión, sobre todo en la década de los noventa. Al respecto diferentes autores han destacado la importancia de la discusión sobre este tema a la hora de redefinir los planes de estudio ${ }^{10}$.

\section{Las implicancias del Humanismo como obstáculo epistemológico para el Trabajo Social}

Bachelard sostiene que para situarse en lo que denominamos el problema del conocimiento científico, no podemos sino aludir a la noción de obstáculo. Su visión del conocimiento rompe con los criterios de acumulación como mecanismo para conocer más. Al contrario el autor plantea que "se conoce en contra de un conocimiento anterior” (Bachelard, 2004:15). Las dificultades en torno al conocer no derivan entonces de la complejidad de los fenómenos a estudiar, o de los problemas (profundamente discutidos por la gnoseología y la epistemología) respecto a los sentidos o la razón humana como herramientas apropiadas para entablar esta relación con la realidad que denominamos conocer. Los obstáculos para conocer no son exógenos, sino que "es en el acto mismo de conocer, íntimamente, donde aparecen (...) las causas de estancamiento y hasta de retroceso, es ahí donde discernimos las causas de inercia que llamaremos obstáculos epistemológicos" (Bachelard, 2004:15). El obstáculo epistemológico está más cerca de lo que pensamos, tanto que no somos capaces de verlo. Para el autor el conocimiento no se divide como clásicamente lo hacemos en conocimiento científico y conocimiento del sentido común, sino que al interior mismo del conocimiento científico funciona un sentido común a-crítico que solidifica y convierte en verdades incuestionables e invisibles que actúan de forma mecánica a una serie de postulados. Es cuando logramos romper con ellos, cuando nos situamos contra ellos, cuando podemos conocer. En tanto "está en la naturaleza de un obstáculo epistemológico ser confuso y polimorfo"

10 Sobre la cuestión de las reformas curriculares y los diferentes perfiles profesionales cfr. Cazzaniga (2009); Coria et al (1999); Jong et al (2003); Rozas Pagaza (2006). 
(Bachelard, 2004:24), entendemos que ésta no es una tesis científica provisoria que una nueva contrastación empírica puede refutar. El tema es más complejo. Funciona como una red diseminada y difusa, que atraviesa nuestra forma de posicionarnos ante la realidad, y que es naturalizada y compartida en tanto hegemónica. "Llega un momento en el que el espíritu prefiere lo que confirma su saber a lo que lo contradice, en el que prefiere las respuestas a las preguntas"11 (Bachelard, 2004:17).

Entender que el Humanismo puede funcionar como obstáculo epistemológico para el trabajador social es sostener que la profesión ha internalizado una perspectiva, la ha convertido en doctrina, en fundamento de la práctica profesional, y que esta serie de derivaciones difusas para la investigación e intervención provenientes del Humanismo funcionan como saber previo que no quiere ser cuestionado. El profesional intenta adaptar lo que ve y lo que hace a sus saberes humanistas. Desentrañar estos mandatos, revisarlos, sería para Bachelard, intentar conocer, ya que “...nada es espontáneo. Nada está dado. Todo se construye” (Bachelard, 2004:16).

Intentaremos entonces en este apartado señalar en algunas de las propuestas derivadas del discurso humanista esbozado por AnderEgg y descriptas en el parágrafo anterior, las características que en sus fundamentos y en sus implicancias prácticas funcionan en la profesión como obstáculo epistemológico. A su vez se realizan algunas propuestas a partir de la descripción de discursos y prácticas críticos al humanismo provenientes del post-estructuralismo.

En su capítulo 3, denominado "Cualidades, capacidades y actitudes vitales que expresan el perfil profesional de un trabajador social inspirado en una concepción humanista”, el autor presenta un listado de estas cualidades, describiendo cada una de las mismas, siendo quince las enumeradas. A continuación las transcribiremos, para luego centrarnos en el análisis de algunas de ellas, seleccionadas con el criterio de impacto que creemos tienen para la práctica profesional:

11 Quizás la preguntas fundantes de Heidegger: “¿Por qué hay algo y no más bien nada?”, “¿Qué es el ser?”, y su interrogante anterior "¿Por qué no nos hemos preguntado esto antes?”, sean un ejemplo de búsqueda de ruptura con una serie de obstáculos epistemológicos propios de su tiempo. 
1. Sensibilidad social y sentido de solidaridad

2. Mística y vocación de servicio

3. Habilidad para sensibilizar, motivar y animar

4. Madurez humana

5. Don de gentes

6. La empatía como capacidad de sintonizar y comprender a los demás

7. La capacidad de diálogo como aspecto fundamental de toda praxis social liberadora

8. La capacidad de escucha activa

9. Convicción y confianza en que la gente puede liberar sus potencialidades para realizarse como persona y resolver sus problemas

10. Importancia de la inteligencia emocional con actitud vital para la acción

11. Fortaleza y tenacidad para enfrentar las dificultades

12. Estilo personal capaz de sustentar los principios y volares de la profesión

13. La alegría de vivir, la risa y el buen humor

14. El pensamiento positivo como ingrediente de una praxis liberadora

15. El compromiso como síntesis y culminación de las cualidades de un trabajador social que haya optado por una praxis liberadora (Ander-Egg, 2010a:47-59)

Respecto de la Sensibilidad social y sentido de solidaridad el autor afirma que "El secreto para comprender a los otros no es el conocimiento sino el amor" (Ander-Egg, 2010a:52). A continuación, previene a sus lectores, sosteniendo que esta frase puede parecer ridícula para los profesionales tecnocráticos y asépticos, para la sociedad competitiva de trepadores y oportunistas que se desentienden de la sensibilidad. Otra vez, el recurso retórico de la metonimia: la parte por el todo. Quienes critican su mirada son per se profesionales desentendidos con el compromiso social e incluso enrolados en la sociedad de la competitividad. 
La alusión a la Mística y vocación de servicio, como cualidad indispensable para el ejercicio de la profesión, ilustran -como en otras frases del texto- la utilización de categorías provenientes del ámbito religioso y filantrópico.

A continuación remarca una serie de capacidades (los ítems del 3 al 6) vinculadas con el manejo de grupos y la oratoria, así como el "carisma" que el trabajador social debe tener para desarrollarse en la tarea con grupos. En relación a estos ítems advierte que esto no implica una actitud de manipulación. Habilidad para sensibilizar, motivar y animar.

Sobre la cuestión del diálogo y la escucha se cree importante confrontar a esta propuesta los aportes de otros autores críticos al Humanismo. En el caso de Nancy (quien rescata el cuerpo como eje, como territorio sin interioridad), él sostiene una diferencia esclarecedora entre oír y escuchar: "Si oír es comprender el sentido (sea en el así llamado sentido figurativo, o en el así llamado sentido propio: oír una sirena, un pájaro, un tambor es ya comprender al menos el contorno impreciso de una situación, de un contexto, sino de un texto) escuchar es extenderse hacia un posible sentido que, por ende, no es inmediatamente accesible" (Nancy, 2002:18). El oír implica un nominar, un cierre que etiquetando clausura el movimiento, la búsqueda. En el oír subyace para el Trabajo Social Moderno, la fuente de información recopilada por la percepción sensorial para describir lo real y objetivo. Será a posteriori, la razón, la lógica, el criterio probado del profesional el que reconstruya intelectualmente el sentido inherente a la cosa oída. El Humanismo moderno como mito y como ideología oye el hombre predefinido, traduce racionalmente cada sonido, cada síntoma, cada demanda, cada necesidad, a la imagen preconstruida que funciona como hipótesis validada una y mil veces por el recorte caprichoso de un oír racionalizado. La realidad es una y racional, reza el presupuesto incuestionable del método científico, tal como lo expresa Samaja (2004:26). El nuevo Humanismo incorpora el criterio de la comprensión, critica fuertemente al positivismo como paradigma tecnificante y vacío, a la vez que propone para llenar ese hueco la reedición de las virtudes cardinales cristianas (fe, esperanza y amor). 
¿Qué oye el trabajador social humanista? Oye el reclamo, el grito de los excluidos. ¿Qué categorías ideologizadas y por lo tanto invisibles a la crítica, tiene introyectadas el trabajador social humanista? O incluso desde una mirada althusseriana: ¿Qué ideologías hablan a través del humanista sin que él lo sospeche siquiera? El trabajador social humanista oye las necesidades insatisfechas, casi antes de que la persona se las enuncie.

Mientras tanto, en la postura de Ander-Egg, para que el diálogo sea auténtico, se suponen algunas exigencias: "Comunicación horizontal y entre iguales; no hay relaciones verticales en las que el trabajador social se sienta superior. No estamos tratando a un cliente, sino a un persona" (Ander-Egg, 2010:67). Son diversas las teorías que desde diferentes enfoques dan cuenta de la complejidad en los vínculos sociales. Desde la psicología social, el interaccionismo simbólico, el enfoque sistémico, el análisis de clase marxista, los estudios feministas, la noción de campo de la sociología comprensiva, el posestructuralismo foucaultiano, entre otros tantos, se pone en discusión la noción de que cuando dos personas se encuentran para dialogar, aunque se encierren en un cuarto y no inviten a nadie más a ese encuentro, no están solos ${ }^{12}$. Miles de determinantes y/o condicionantes de género, etáreos, culturales, de clase, de poder, de estatus, cientos de representaciones sociales diferenciadas, cruzadas, atravesamientos ideológicos, etc., se hacen presentes en la cita. Estas dos personas no están solas. Pero tampoco están acompañadas por factores exógenos que circulan libremente por la habitación. Hay una compleja trama en esos cuerpos que son dos, pero que han sido resignificados, hasta podríamos decir creados y recreados por estos elementos. No hay interioridad en el cuerpo de los posestructuralistas. No hay elementos "entre" ni "adentro". Hay cuerpos que ocupan espacios determinados socialmente. En este contexto: ¿Por qué tomamos a la persona como hecho? ¿Qué significa comunicación horizontal y entre iguales? ¿Qué significa que no estamos tratando a un cliente sino a

12 Un análisis sobre la cuestión de los determinantes sociales en la relación Trabajador Social -sujeto pude encontrarse en Karsz (2010). 
una persona? ¿Qué es "una persona”? Aquí llegamos nuevamente al Humanismo como ideología. Estamos tratando a una persona. No hay nada para pensar en esta afirmación. La persona es lo dado. La oímos y no la escuchamos porque ya todos sabemos qué es y qué no es una persona. Porque todos somos personas. Somos iguales. Este postulado funciona como argumento para entablar un cierto tipo de comunicación y a la vez como fin teleológico del "Trabajo Social testimonio de lo Humano". Fuente y culmen (como la eucaristía cristiana). Somos humanos. Esta clausura argumentativa y finalística nos cierra el camino para la escucha. Impide el extrañamiento. Impide ver los condicionantes que nos construyen como "personas", y que hace que haya en cada momento histórico, en cada formación social determinada, un criterio hegemónico del ser persona, en disputa con otros. Yo soy persona, soy libre, tengo razón y voluntad. Ese otro, que no es mi cliente, sino una persona, tiene mis mismas características básicas. Sí puedo dejarme sorprender oyendo sobre su perfil de personalidad, o sobre los avatares de su vida cotidiana, pero no sobre su "esencia". Su "esencia" es la misma que la mía. Somos seres humanos. Esto garantiza la horizontalidad. Y aquí llegamos a la falacia, al peligro de sentirnos tranquilos porque nuestros axiomas nos custodian de prácticas autoritarias. Sostengo comunicaciones horizontales, estoy aliviado, soy un profesional humanista. El otro es una persona igual a mí. Y aquí agregamos, tiende al mismo fin que yo, el fin humanista de la fe, la esperanza y el amor, el horizonte de la libertad. Más adelante Ander-Egg agrega: "Ni los sectarios ni los dogmáticos tienen disposición para el diálogo"; y luego: "En el diálogo tengo que expresar... el derecho a la diferencia y la apertura de lo universal” (2010:67). ¿Qué es lo universal? ¿No habrá algo de dogmático en la idea de "lo universal"? Podemos interpretar lo universal con las banderas históricas del Humanismo, que son las de la Revolución Francesa: libertad, igualdad, fraternidad. Es Levi Strauss quien, como ya hemos afirmado, desentraña el sentido de la revolución como mito, como relato que se escinde de su realidad históricopolítica determinada para funcionar como relato explicativo, como génesis y como propuesta teleológica. Ya Laclau (2008a; 2008b), re- 
tomando a Lacan, profundiza en sus análisis la idea de "significante vacío”. El Humanismo reniega de esta idea. Se obstina en pensar que hablar de la libertad como un significante vacío es caer en una postura nihilista que abre las puertas al peligro de lo in-humano, de lo nolibertario. Sin embargo, podemos invertir el análisis. Basta analizar por ejemplo las prácticas de médicos higienistas en nuestro país en el siglo pasado ${ }^{13}$, quienes desde el ideario humanista y emancipador, en el mismo movimiento de mejorar eficaz y notoriamente los índices de tuberculosis en los sectores populares, generaron procesos de normalización, violencia simbólica y material en muchas de sus medidas preventivas, control social, imposición de pautas culturales -so pretexto de ser pautas higiénicas-, creando un mapa de buenos y malos enfermos, culpables y víctimas, que como podemos observar, poco tiene que ver con la emancipación. Yendo más lejos aún, podemos tomar el análisis de Agamben (2007) respecto del Estado de Excepción, de vida nuda y del homo sacer: cada nueva conquista en el marco del Estado de Derecho, para el respeto de la dignidad humana, tiene una contratara macabra ${ }^{14}$. El Estado de Excepción es la verdadera norma. En la historia, nunca todos somos humanos, nunca todos somos sujetos de derecho. El Humanismo cuenta con pocas herramientas para analizar estos fenómenos que sin embargo deberían constituir una preocupación intelectual y práctica de los trabajadores sociales. Con respecto a lo que Ander-Egg denomina la "convicción y confianza en que la gente puede liberar sus potencialidades para realizarse como persona y resolver sus problemas" también podemos ensayar algunas reflexiones. En este ítem es interesante rescatar la reflexión del autor respecto de la necesidad de confiar en los otros. Esto implica que en el desarrollo de nuestras acciones podemos ser decepcionados, pero que si somos maduros "sabemos que es preferible sufrir decepciones que vivir como personas escépticas respecto a las personas, como

13 Un interesante análisis sobre el tema del Higienismo y la Ilustración lo encontramos en Carballeda (2005).

14 Se pueden encontrar reflexiones respecto del antinormativismo agambeneano, en particular desde una relectura del mismo para el Trabajo Social, en Hermida (2009). Allí también se encuentran las críticas que autores como Bauman, Negri y Laclau realizan a la propuesta de Agamben. 
si todas ellas fueses "ingratos" potenciales" (Ander-Egg, 2010a:74). Aquí otra vez encontramos la conexión con el enfoque de la caridad y la filantropía. La gratitud y la ingratitud. ¿Quién debe darnos las gracias y por qué? ¿Qué sentido tiene hablar de gratitud o ingratitud en el marco del ejercicio de una profesión? Sólo tiene sentido si entendemos que el ejercicio de nuestra actividad profesional parte de nuestro amor y buena voluntad, y no de la tarea que debemos cumplir, dado que es nuestro trabajo, que estamos capacitados para esto, que recibimos un sueldo por realizarlo, y que nos desarrollamos en el marco de consideraciones éticas del ejercicio profesional debidamente regladas, como así también de premisas derivadas del enfoque epistemológico al que adhiera cada profesional.

En relación a la "fortaleza y tenacidad para enfrentar las dificultades" que propone el autor como otra cualidad básica del trabajador social, encontramos el retorno al tema de la gratitud, ya que siempre que se trabaja con gente "se tropezará con problemas, desde la apatía hasta la ingratitud y el rechazo" (Ander-Egg, 2010a:77). A su vez, frente a la falta de reconocimiento de la profesión, y a los diversos contratiempos y dificultades, propone como cualidades la fortaleza, la tenacidad y la perseverancia en contraposición al quejido: "no tiene sentido la enfermiza proclividad al quejido que ha existido -y que aún existe- dentro de la profesión, como si con quejarse se venciesen las dificultades" (Ander-Egg, 2010a:78). Plantear que la queja no tiene sentido y que incluso hace daño, es una afirmación que puede convertirse en riesgo, ya que de ella podemos derivar en sostener que la protesta y la denuncia no tienen sentido. Que lo indicado es soportar con tenacidad ya que "necesitamos ser animosos, cordiales, y nuestros comportamientos deben expresar pensamientos positivos" (Ander-Egg, 2010a:78). Más adelante advierte sobre la necesidad de luchar frente a las adversidades pero en el marco de la capacidad de resiliencia. Este concepto, propuesto por el Banco Mundial y los organismos internacionales en el marco del consenso de Washington, ha sido criticado por diversos intelectuales en tanto opera como justificación de la exclusión, rescatando lo positivo de ésta: cuanto peor se está, mayores son las posibilidades de soportar. Y a esta lectura 
agregan que esta capacidad resiliente debe ser aprovechada por los técnicos y profesionales de lo social.

A las orientaciones de tipo: "sustentar los principios y volares de la profesión; la alegría de vivir, la risa y el buen humor; el pensamiento positivo como ingrediente de una praxis liberadora" (de las que poco hay para comentar), agrega la idea de "el compromiso como síntesis y culminación de las cualidades de un trabajador social que haya optado por una praxis liberadora". En este apartado, que es el último, puede analizarse sin necesidad de hacer una exégesis profunda, la fuerte influencia de la doctrina social cristiana en los aportes de Ander-Egg. Al hablar del compromiso plantea que es "una opción que polariza todas las energías al servicio de una causa o de un ideal" (2010a:86). La idea de opción, de servicio, y de ideal son propias de la estética cristiana. Termina su libro con una evocación a la fe, la esperanza y el amor (valores que se encuentran en el Nuevo Testamento, particularmente en la epístola de Pablo a los Romanos, y conocidas para la teología como "virtudes cardinales").

\section{Escuchando los desafíos al Trabajo Social por fuera del Humanismo}

¿Qué efectos, que nuevas puertas abriría al Trabajo Social una lectura no humanista de las situaciones en las que interviene? Tomemos como ejemplo para el análisis, las reflexiones de Foucault respecto del Goulag: "Más que buscar en estos textos [de Marx y Lenin] lo que podría condenar al Goulag de antemano, se trata de preguntarse qué es lo que en ellos lo ha permitido, qué es lo que continúa justificándolos, qué permite hoy aceptar esta intolerable verdad. La cuestión del Goulag no debe plantearse en términos de error (reduccionismo teórico), sino de realidad" (Foucault, 1977:165-166). El autor realiza una serie de apreciaciones de corte genealógico de profunda riqueza heurística. En principio propone para acercarse a la cuestión del Goulag, rechazar el análisis en términos de causas porque este enfoque científico de explicación causal derivaría en delimitar la cuestión 
del Goulag en términos negativos, como disfunción a corregir. ¿Cuál fue el "error" que "causó" este escándalo? Al contrario, plantea abordar la situación en su positividad, ya que, como él mismo afirma: "el Goulag no es un residuo o una consecuencia. Es un presente candente" (Foucault, 1977:165).

En este enfoque ya puede observarse una diferencia sustancial con la mirada humanista. Aquí no se intenta analizar la realidad en tanto desviaciones respecto de un proyecto emancipador que nos conducirá al telos perseguido en nuestra utopía. El Goulag es también Modernidad. No es una alteración o un error cometido que traiciona a la Moderndiad. Continuando su análisis Foucault advierte sobre el peligro del entrecomillado. Plantea evitar la explicación del Goulag a partir de la afirmación de que el socialismo soviético no es socialismo, sino un socialismo entre comillas, ya que esto implicaría pensar que el Goulag es posible porque existe en un socialismo que no es tal, pero implicaría también afirmar que el único socialismo real es el ideal, el que está en nuestros libros, en nuestras cabezas. Otra vez encontramos una diferencia con el Humanismo, en el seno del cual suelen escucharse planteos del tipo: "lo que pasa aquí es que en realidad no hay Democracia”. Los derechos se vulneran porque la democracia aun no llegó, no es la real, no es la ideal. Las prácticas profesionales no surten el efecto esperado porque en realidad no estamos haciendo Trabajo Social, porque el verdadero Trabajo Social es el ideal. Esto nos impide comprender, y por lo tanto transformar nuestra realidad. Por último, Foucault plantea enfocarse en la resistencia. ¿Qué es lo que hace posible resistir al Goulag? Este punto es de una gran riqueza si hacemos un paralelo con las situaciones con las que trabajamos a diario desde la profesión. ¿Qué es lo que hace posible las prácticas de resistencia y de construcción de los sectores populares? ¿Qué hace viable ciertas experiencias innovadoras en la profesión? En general las posturas lineales observan lo que falta, o con suerte, toman en cuenta las potencialidades, pero pocas veces se propone un análisis genealógico, de tomar lo insoportable en su positividad, no como error del sistema, y acercarse a lo que resiste y propone novedad más allá de sus beneficiosas consecuencias prácticas, abordándolo en su 
génesis, en su sentido, ¿Cómo, por qué, fue posible este recorrido innovador, esta construcción que desafía lo establecido? De esta forma, la lectura no humanista del Goulag de Foucault traza pistas para pensar una lectura no humanista de las situaciones que se transitan en la intervención.

\section{Conclusiones e interrogantes}

Hablar del Humanismo como obstáculo epistemológico no implica hablar de un Trabajo Social sin valores, sin respeto por la dignidad humana, por la libertad, por los derechos humanos. Muy por el contrario, es permitirse refrescar la mirada, trascender lo dado incuestionable, dejar de entender los valores como objetos (tal como advertía Heidegger), como Mito (Levi Strauss) como discurso universalizante y como ideología (Althusser).

Aquí me permito retomar una idea de Teresa Matus ${ }^{15}$ : hoy pensar la ética desde el umbral post-metafísico, implica un giro, dejar de poner el eje en las opciones morales y valores del Trabajador Social (qué debe hacer el profesional cuando la adolescente con la que trabaja quiere abortar, o situaciones de este tipo), para abrirse a la discusión ideológica, a un situarse en el marco de los diversos proyectos éticospolíticos que existen en la profesión, a la coherencia epistemológica y metodológica que nuestras investigaciones e intervenciones reclaman. Y en la misma línea como Saibene ${ }^{16}$ afirmara en su Seminario de Epistemología, recuperar la idea de que: "el eclecticismo es la muerte del pensamiento". Abrirse a entender los llamados valores como significantes vacíos, que permitan la organización y la emergencia de lo nuevo a través de lo que Laclau (2008a) llama cadenas equivalenciales de demandas. Trabajar por una objetividad sin neutralidad, tal como propone Boaventura de Souza Santos (2005) a las Ciencias

15 Reflexiones realizadas por Teresa Matus en el marco del Seminario "Propuestas Contemporáneas en Trabajo Social”, del Doctorado en Trabajo Social de la UNR, dictado en el año 2009.

16 Reflexiones realizadas en el marco del Seminario "Epistemología de las Ciencias Sociales" del Doctorado en Trabajo Social de la UNR, dictado por la Dra. Alicia Gonzalez-Saibene en el año 2009. 
Sociales, pero reinventando la emancipación, realizando una crítica a la Razón Moderna y sus consecuencias para la construcción de conocimiento y para las prácticas sociales.

Son varias las aristas respecto del debate en torno al Humanismo en el Trabajo Social que quedan sin abordar en este trabajo. En principio sería interesante preguntarse por qué este debate no es tal. Haciendo una lectura exploratoria, no exhaustiva sobre el tema, se observa que si bien hay textos académicos sobre Humanismo y Trabajo Social, en general los mismos plantean este vínculo de forma directa, incuestionada, haciendo alusión a los aportes del Humanismo hacia la profesión y viceversa. Pero no existe un interés significativo con respecto a discutir cuáles son los fundamentos epistemológicos del Humanismo (debate central al interior de las ciencias sociales en la década del 60, pero prácticamente ausente en la historia de nuestra profesión) y sus consecuencias en el ejercicio de la profesión.

Por otra parte, otra deuda de este trabajo es la de abordar la cuestión del vínculo mismo entre humanismo y Trabajo Social, en términos históricos, arqueológicos o genealógicos. ¿Cuándo el Trabajo Social (o parte importante de él) "toma" el Humanismo como "programa", como "horizonte", como "fundamento"? ¿De la mano de qué autores, de qué enfoques (dentro de la variada gama de "Humanismos" existentes) llega esta postura a hacerse presente en el Trabajo Social hoy en nuestro país? ¿Hay una conexión explícita en el paso de un modelo caritativo religioso a uno filantrópico y de éste a uno humanista, o el proceso tiene otras complejidades? ${ }^{17}$ Otra interesante tarea sería la de analizar los postulados y principios del Trabajo Social a la luz de los debates aquí enunciados.

Para finalizar, se cree que el Humanismo puede caer fácilmente en una visión evolucionista de lo social. Los sectores postergados deben estar clamando por su liberación, por su inclusión, por poder ser más humanos, más incluidos, más libres. Si ya tenemos las respuestas,

17 Existen producciones que abordar desde distintas perspectivas la historia de la profesión y las influencias que le dieron origen tal como hemos apuntado en otra nota al pie. La propuesta aquí es profundizar en un aspecto particular de la misma que es rol que jugó y juega el Humanismo, y las diferentes corrientes humanistas que hicieron pie en la profesión. 
¿qué preguntamos cuando preguntamos? Los trabajadores sociales entonces preguntamos: qué les falta para llegar aquí, a donde dice el Humanismo que hay que llegar (necesidades y demandas) $\mathrm{Y}$ algunos otros, más influidos por alguna corriente crítica podríamos preguntar: ¿qué tienen para aportar para este cambio? (potencialidades). Incluso hasta también, los más participativos podemos interrogar: ¿por cuál calle quieren recorrer el camino a la meta prefijada? (asambleas para el logro del desarrollo humano). Pero no salimos de las díadas, desarrollo/subdesarrollo, progreso/orden, inclusión/exclusión, derecho vulnerado/derecho asistido, autoritarismo/participación. No abrimos a la emergencia de lo Otro. Buscamos la transformación sin la comprensión porque ya comprendimos qué es lo humano y hacia dónde va, con oír alcanza, la escucha es angustia, duele suspendernos, esperar antes de nominar, dar espacio al cuerpo que se resiste al catálogo, a la enumeración, esto nos impide aplicar nuestras técnicas, nos hace no profesionales. Como si tuviéramos miedo de pensar lo Otro, diría Foucault. Matus nos propone pensar el Trabajo Social "como una forma de ver que funda un hacer peculiar". Esta particular manera de ver y de escuchar de nuestra profesión puede ser recreada si cuestiona las concepciones que la orientan, y que en tanto se naturalizan pueden convertirse en obstáculos epistemológicos. Se ve distinto sin los anteojos del Humanismo. El Trabajo Social puede ser una prácticaotra si en tanto forma de ver y de escuchar, ve y escucha desde otro lugar. La propuesta es muy simple. Callarse un poco, callar nuestro mandato Humanista. Quizás valga la pena intentar escuchar y ver sin el filtro del Humanismo. Podríamos sorprendernos.

\section{Referencias bibliográficas}

AGAMBEN, G. Homo sacer. Sovereign Power and Bare Life. California, Santandarford University, 1998.

AGAMBEN, G. Estado de excepción. Buenos Aires, Adriana Hidalgo editora, 2007.

ALTHUSSER, L. La revolución teórica de Marx. México, Siglo XXI editores, 2004. 
ANDER EGG, E. Humanismo y Trabajo Social. México, Universidad Autónoma de Sinaloa, Facultad de Trabajo Social, Culiacán, 2010.

BACHELARD, G. La formación del espiritu científico. $25^{\circ}$ edición en castellano. México, Siglo XXI, 2004.

BARTHES, R. Fragmentos de un discurso amoroso. Buenos Aires, Siglo XXI editores, 2009.

CARBALLEDA, A. El Trabajo Social desde una mirada histórica centrada en la intervención. Del orden de los cuerpos al estallido de la sociedad. Buenos Aires, Espacio Editorial, 2006.

CARBALLEDA, A. "Algunas consideraciones sobre la reflexión histórica en Trabajo Social. Una mirada genealógica a la intervención en lo social." en: FERNANDEZ SOTO, S. (coord.) El Trabajo Social y la cuestión social. Crisis, movimientos sociales y ciudadanía. Buenos Aires, Espacio Editorial, 2005.

CAZZANIGA, S. Hilos y nudos. La formación, la intervención y lo político en el Trabajo Social. Buenos Aires, Espacio Editorial, 2009.

CORIA, A. et al. Currículum e Investigación en Trabajo Social. Encuentro Académico Nacional de FAUATS. Buenos Aires, Espacio, 1999.

CUSSET, Y y HABER, S (dir.) Habermas/ Foucault. Trayectorias cruzadas. Confrontaciones críticas. Buenos Aires, Nueva Visión, 2007.

DE SOUZA SANTOS, B. Renovar la teoría crítica y reinventar la emancipación social. Buenos Aires, CLACSO Ediciones, 2005.

DERANTY, J. "Derecho y democracia entre disolución biopolítica y reconstrucción normativista: Agamben, Foucault, Habermas, Honneth", en: CUSSET, Y. y HABER, S. (dir) Habermas/ Foucault. Trayectorias cruzadas. Confrontaciones críticas. Buenos Aires, Nueva Visión, 2007.

DERRIDA, J., CAPUTO, J. La deconstrucción en una cáscara de nuez. Buenos Aires, Prometeo, 2009.

DEWEY, J. Naturaleza humana y conducta. México, Fondo de Cultura Económica, 1964.

FOUCAULT, M. ¿Qué es un autor? Córdoba: Litoral, la función secretario, 1998. [En línea: 16/3/2012] Disponible en: http://exordio.qfb.umich.mx/archivos\%20pdf\%20 de\%20trabajo\%20umsnh/LIBROS\%2014/Foucault\%20Michel\%20\%20Que\%20Es\%20 Un $\% 20$ Autor $\% 20 \% 5$ BSicario $\% 20$ Infernal $\% 5$ D.PDH

FOUCAULT, M. Las Palabras y las Cosas: una arqueología de las ciencias humanas. Buenos Aires, Siglo XXI editores, 2002.

FOUCAULT, M. "Entrevista sobre la prisión, el libro y su método", en: FOUCAULT, M. Microfísica del poder. Madrid, Ediciones de la piqueta, 1992. 
FOUCAULT, M. "Verdad y poder”, en: FOUCAULT, M. Microfísica del poder. Madrid, Ediciones de la piqueta, 1992.

FOUCAULT, M. "Poderes y estrategias. Entrevista con Michel Foucault”, en: FOUCAULT, M. Microfísica del poder. Madrid: Ediciones de la piqueta, 1992.

FOUCAULT, M. La Arqueología del Saber. México, Siglo XXI editores, 1995. GONZÁLEZ-SAIBENE, A. "El objeto de intervención profesional: un mito del Trabajo Social”. Rosario, FFS, 2007.

HEIDEGGER, M. Carta sobre el Humanismo. 1947. [En línea: 10/05/2010 ]. Disponible en: http://www.libroos.es/libros-de-filosofia/varios/4216-heidegger-martin-carta-sobreel-humanismo-htm.htm.

HEIDEGGER, M. El Ser y el Tiempo. México, Fondo de Cultura Económica, 1951.

HERMIDA, M. "Trabajo social, riesgo y nuda vida. Entre la política reflexiva y la política radicalizada”, en: CUELLA, S. (comp.) III Encuentro Argentino y Latinoamericano de Trabajo Social. Escenario Político de Latinoamérica: El desafío del Pensamiento Crítico en las Ciencias Sociales y el Trabajo Social. Córdoba, UNC, 2 y 3 de julio de 2010. ISBN: 978-950-33-0786-1.

JONG, E. et al. Formación académica en Trabajo Social: una apuesta politica para repensar la profesión. Buenos Aires, Editorial Espacio, 2003.

KARSZ, S. “¿Qué pasa con lo humano en una sociedad fundada sobre el ideal del 'riesgo cero'? Propuestas parciales para un debate no necesariamente consensual”, en: Revista Millcayac. Anuario de Ciencias Políticas y Sociales. Universidad Nacional de Cuyo. $\mathrm{N}^{\circ} 8$, 2010.

LACLAU, E. La razón populista. 1ra edición. 3ra reimpresión. Buenos Aires, Fondo de Cultura Económica, 2008a.

LACLAU, E. Debates y combates. Por un nuevo horizonte de la politica. Buenos Aires, Fondo de Cultura Económica, 2008b.

LEVI STRAUSS, C. El pensamiento salvaje. México, Fondo de Cultura Económica, 2009, (1962).

MARTINELLI, M. Servicio Social: Identidad y alienación. Sao Paulo, Cortez Editora, 1992.

MATUS SEPÚLVEDA, T. "La intervención social como gramática”, en MATUS SEPÚLVEDA, T. Apuntes sobre intervención social. 1992. [En línea: 10/01/2011] Disponible en: http://www.fcp.uncu.edu.ar/upload APUNTESSOBREINTERVENCIONSOCIAL.pdf.

MEAD, G. Espíritu, persona y sociedad. México, Paidós, 1993.

MIRANDA ARANDA, M. De la caridad a la ciencia: Trabajo Social, la construcción de una disciplina científica. Buenos Aires, Espacio, 2010. 
MIRANDA ARANDA, M. De la caridad a la ciencia II: Influencias del pragmatismo y el interaccionismo simbólico en Trabajo Social. Buenos Aires, Espacio, 2013.

NANCY, J. A la escucha. Buenos Aires, Amorrortu, 2007.

NETTO, J. Capitalismo Monopolista y Servicio Social. Sao Paulo, Cortez Editora, 1992.

NIETSZCHE, F. La gaya ciencia. Buenos Aires, Andrómeda, 2004.

PARRA, G. Antimodernidad y Trabajo Social. Orígenes y expansión del Trabajo Social Argentino. Buenos Aires, Espacio, 2011.

RICHMOND, M. Caso Social Individual. Buenos Aires, Escuela Nacional de Salud Pública, 1962.

ROZAS PAGAZA, M. (coord.) La formación y la intervención profesional: hacia la construcción de proyectos ético-políticos en Trabajo Social. Buenos Aires, Espacio, 2006.

SAMAJA, J. Epistemología y metodología. Elementos para una teoría de la investigación científica. 3ra edición, 4ta reimpresión. Buenos Aires, Eudeba, 1998.

SARTRE, J. Critica de la razón dialéctica. Tomo I y II, 1960. [En línea: 05/03/2010] Disponible en: http://www.buscarlibrospdf.com/crtitica-de-la-razon-dialectica.htm

TRAVI, B. "Construcción de la Identidad, Historia y Formación Profesional”, en: IBAÑEZ, V. (comp.) Historia, identidad e intervención profesional. III Encuentro interuniversitario de investigadores en Trabajo Social. Grupo GIITS. Mar del Plata, Ediciones Suárez, 2011.

Recepción: 27/05/2015

Aceptación: 03/08/2015 